\title{
What Makes a Good Consultant?
}

\section{A GP's view}

\author{
A C J MCLEAN
}

What makes a "good" consultant? I suspect the same ingredients that make a "good" GP only the emphasis may differ. Hard work? Undoubtedly. I have met consultants who were enthusiastic on the theme; unfortunately I was working for them at the time. On a sadder note, I have also seen those who were intoxicated with work as an attempt to escape from themselves. Most of the consultants I have met I have liked enormously, and some I have even loved dearly. As an addicted consultant watcher both in the United Kingdom and abroad I offer the personal view of a country GP.

\section{Qualities}

"Presence" is the hardest quality to define, but one of the most important. It has nothing to do with pomposity and is readily recognised by patients. It is a powerful therapeutic tool. It may have something to do with having high standards which don't change whatever the company. The late Professor "Wully" Hamilton certainly displayed it when he was inadvertently addressed as "Oi mush" by an extravert student. "Professor Mush, if you please," was the gentle reply. Order restored, nobody hurt, and the first flames of fierce loyalty were lit. Presence, rather than charisma, implies the ability to give patients the confidence that results from realising that their worries are thought to be important.

Tolerance would be high on my list of qualities in a consultant. It should be possible to loathe a vice yet empathise with the patient suffering as a result. Pompous unproductive tirades against the alcoholic, the smoker, the fat, the plain stupid or merely filthy are not rare. According to the Talmud God appeared to Abraham and said, "I have borne that ignorant man for seventy years; could you not have patiently suffered him for one night?" I suspect that the consultants who abuse my patients are equally scathing of my crass mistakes.

Communication: much has been written, but there is still chaos. I put on a pedestal those consultants who themselves compose the summary of a complex case for the GP. How can one plead for cognitive as well as procedural skills if those who have the most skills undervalue them by delegating to their juniors?

As for merit awards, I would give priority to the consultants who best show how clinical decisions are reached. At present the lion's share of these awards goes to those who investigate the causes and mechanisms of disease. The sheer excitement should be reward enough. "Research which directly concerns the clinical decision making process seems less esteemed, as shown by the fact that reports of controlled therapeutic trials and critical evaluation of new diagnostic methods only represent a small minority of all papers published in medical journals." Give me consultants who show how to obtain and weigh evidence, ${ }^{2}$ organise those controversial problem lists, ${ }^{3}$ and perhaps are the modern pioneers of "decision analysis." An estimated $98 \%$ of all episodes of illness that result in a medical consultation are managed wholly in general practice. ${ }^{5}$ It seems fair

15 Cattell's Lane, Waterbeach, Cambridge CB5 9NH

A C J MCLEAN, MB, BS, general practitioner therefore to acknowledge merit in the consultants who most help the diagnostic decision process for those of us at the "pit face." GPs get the patients they deserve; perhaps consultants get the GPs they deserve. A stronger case might be made for consultants who educate the patient directly. There have been spectacular advances in treatment in both diabetes and asthma. But the mortality and morbidity in the former is falling and in the latter is not. Perhaps it is not too fanciful to give the credit to the better collaboration between diabetic physicians and educational scientists?

Prickly problems of private practice. One approach to working out how much to charge that intrigued me was to charge a fixed proportion of the current value of the patient's car. This is perhaps a fair indicator of the patient's life values. It is always appreciated when consultants justify their pecuniary worth to patients. It is mostly accepted without rancour. Occasionally it is impossible for a GP to do it for them. It is reassuring how many seem to be aware of the spirit of Dr Isaac Watts's dictum:

Blest is the man whose bowels move and melt with pity for the poor.... He in his time of greatest need Shall find the Lord has bowels too.

Technical ability. What a luxury to gloss over this. National Health Service consultants have gone through a mostly fair if somewhat chancy initiation. GPs by contrast are thankfully still an incredibly mixed bunch of mavericks. Consultants who have been in general practice are easily discernible by their ability to serve equally the best and the worst, as with their patients. Perhaps consultants have an undue fear of making diagnostic mistakes. Now that "general" physicians and surgeons are not so valued the end result of some referrals is a letter stating that the problem is "not in their field." Endless shunting of patients may be avoided by confident "informed uncertainty." Patients accept this surprisingly well, as they realise it implies an open mind. GPs are also aware that thoroughness and persistence more often than brilliance lead to the correct diagnosis.

\section{Conclusion}

"The superior man is easy to serve, but difficult to please, for he can be pleased by what is right, and he uses men according to their individual abilities. The inferior man is difficult to serve, but easy to please, for you can please him by catering to his weaknesses without necessarily being right and when he comes to using men, he demands perfection."

Confucius

\footnotetext{
References

1 Wulff HR. Rational diagnosis and treatment. An introduction to clinical decision making. 2nd ed. Oxford: Blackwell, 1981.

2 Pappworth MA. A primer of medicine. 4th ed. London: Butterworths, 1978.

3 Weed LL. Medical records that guide and teach. N Engl f Med 1968;278:593-600, 652-7.

4 Sox HC Jr. Decision analysis: a basic clinical skill? N. Engl f Med 1987;316:271.

5 Weatherall DJ, Ledingham JGG, Warrell DR, eds. Oxford textbook of medicine. 1st ed. Oxford: Oxford University Press, 1983:section 2.5 .

6 Coope R. The quiet art. Edinburgh: $\mathrm{E}$ and S Livingstone, 1952.
} 